\section{Care needs of elderly people with schizophrenia}

\author{
Assessment of an epidemiologically defined cohort in Scotland
}

SEAMUS V. McNULTY, LAING DUNCAN, MARGARET SEMPLE, GRAHAM A. JACKSON and ANTHONY J. PELOSI

\section{Background Little is known of the needs of elderly patients with psychotic illnesses.}

\begin{abstract}
Aims To measure the care needs of an epidemiologically based group of patients over the age of 65 years suffering from psychotic illness, using a standardised assessment.
\end{abstract}

Method All patients aged 65 years and over with a diagnosis of schizophrenia and related disorders from a defined catchment area were identified. Their health and social care needs were investigated using the Cardinal Needs Schedule.

Results The l-year prevalence of schizophrenia and related disorders was 4.44 per 1000 of the population at risk. There were high levels of unmet need for many patients, including those in National Health Service (NHS) continuing-care beds.

\section{Conclusions Many needs were}

identified, all of which could be addressed using the existing skills of local health and social care professionals. The investigation raises serious concerns about standards of hospital and community care for elderly patients with schizophrenia. The findings may be unique, reflecting long-standing problems within a particularly hardpressed part of the NHS. However, it is not known whether a similar situation exists in other parts of the UK.

Declaration of interest None. The study was funded by the Chief Scientist Office of the Scottish Executive.
The serious concerns about the adequacy of care for people with severe mental disorders in the UK have concentrated almost solely on young adults. This may be due to the rarity of violent behaviour by elderly patients (Rodriguez-Ferrera \& Vassilas, 1998). Also, in this age group neurodegenerative diseases dominate health care policy and research activity. There have been few investigations of the care of older people with psychotic illnesses. Some British studies have given encouraging results (Perkins et al, 1989; Leff, 1993; Holloway et al, 1994). For example, the Team for Assessment of Psychiatric Services followed up elderly patients discharged after prolonged hospital admission. Their programme of care was 'highly successful ... perhaps more than any other sector of the former long stay population, ageing schizophrenic patients and those suffering from dementia proved capable of resettling successfully within the community' (Trieman \& Wills, 1996). We investigated the prevalence of schizophrenia and related disorders in elderly people from a defined catchment area and used a standardised needs assessment to evaluate the quality of health and social care.

\section{METHOD}

The study has been informed by four overlapping principles that have evolved from policy documents (the National Health Service and Community Care Act 1990) and previous health services research (Brewin et al, 1987; Stevens \& Gabbay, 1991; Wing, 1992; Marshall, 1994; Murray et al, 1996). First, in assessing treatment outcomes it is insufficient to identify only patients' problems and suffering (Matthew, 1971). According to Wing (1992), this has to be followed by assessment of needs: 'a need for care exists when an individual has an illness or impairment for which there is an effective and acceptable method of intervention' [italics added]. This mirrors good clinical practice and avoids giving the impression that professionals, families and even patients are somehow failing when they are unable to combat incurable illness.

Second, the views of individual patients are paramount in deciding whether they will accept a potentially effective intervention and therefore whether they currently have a need for care in this area (Marshall et al, 1995). This can be overruled only in special circumstances, for example when the patient is a risk to self or others.

Third, deciding what interventions could be effective requires expert professional knowledge. This may be considered a rather old-fashioned approach. However, needs assessment in psychiatry sometimes leads to creation of a 'wish list' which fails to differentiate effective and ineffective interventions.

Fourth, if an illness can impair judgement, evaluation of quality of care must include those not in receipt of services as well as those who are receiving assistance. In our opinion, this is the most important principle in evaluating the care of people with any serious psychiatric or neuropsychiatric condition.

\section{Study area}

The investigation was carried out in the towns of Hamilton, Blantyre, Larkhall, Stonehouse, Bothwell, Uddingston, Bellshill and Viewpark (referred to below as Hamilton and Bellshill) with approval from the research ethics committee of the Lanarkshire Health Board. The total population in 1998 was 155 696, with 20292 persons aged 65 years and over. The major part of the study area had previously formed the old Hamilton local government district, which has been rated the eighth mostdeprived district in Scotland (out of 56), based on deprivation indices (Carstairs \& Morris, 1991) applied to the 1991 census (McLoone, 2000). The overall Carstairs deprivation score for Hamilton district was 0.61 , with scores for individual towns ranging from 3.7 for Blantyre to -2.3 for Uddingston and Bothwell. Viewpark had a Carstairs score of 3.3 and Bellshill a score of 3.2 (the third and fourth highest levels of deprivation for towns in Lanarkshire).

Until about 10 years ago Lanarkshire mental health services were dominated by Hartwood Hospital, a hugh, isolated Victorian asylum. This hospital is set for 
final closure in 2003. Services for elderly people with mental illness in Hamilton and Bellshill now include acute assessment beds in two local district general hospitals and a geriatric community unit. There are longstay beds in Hartwood and Cleland Hospitals. As in other parts of the west of Scotland, the National Health Service (NHS) has contracted with a private nursing home to provide 'partnership' beds staffed by registered mental nurses. The NHS consultants have direct admitting rights and remain the responsible medical officers. Community mental health teams (CMHTs) for elderly patients in Lanarkshire were established in 1995. At the planning stage they were envisaged as teams for the care of patients with dementia. When they began work their remit included all other mental illnesses, although without additional resources.

\section{Study group}

All participants were aged 65 years or over during the period 1 January to 31 December 1998. They had a home address in the study area during this period or else they had been in continuous long-term care in one of the Lanarkshire in-patient facilities and had been originally admitted from a Hamilton or Bellshill address. The NHS-private partnership home was situated in Bellshill and all residents with a relevant diagnosis were included. Patients had schizophrenia or a related disorder, operationally defined as any of the following diagnostic categories from DSM-III-R (American Psychiatric Association, 1987): schizophrenia, schizophreniform disorder, delusional disorder, atypical psychosis and schizoaffective disorder. Those with learning disability who fulfilled the above criteria were included. Potential participants were identified from the following sources.

(a) The Information and Statistics Division of the NHS in Scotland provided hospital discharge data for the past 20 years. Any ICD-9 or ICD-10 diagnosis (World Health Organization, 1978, 1992) that could indicate a schizophreniform illness led to further investigation of eligibility.

(b) Current and past patients of the local psychiatric services who had a relevant or possibly relevant clinical diagnosis were identified by trawls through hospital records, community nursing notes, and appointment diaries. (c) Visits were made to the acute assessment wards, the local community hospital, the long-stay wards at Hartwood and Cleland Hospitals, and the partnership nursing home.

(d) The case notes of all patients with learning disability aged 65 years or over, who remained in hospital care and who originated from the study area, were examined.

(e) Case records of patients on local longstay geriatric medicine wards were similarly examined.

(f) The 18 general practices in the area were contacted with names of relevant patients on their lists whom we had identified. One practice informed us of two additional patients who potentially fulfilled inclusion criteria.

(g) With the assistance of the local CMHT, residential and nursing homes were contacted and an attempt was made to identify any undiagnosed case of psychotic illness. None was found.

(h) Contact was made with the local social work department but they were unable to assist, for reasons of confidentiality.

All psychiatric case notes of potential study participants were examined by the research psychogeriatrician (S.V.M.) using OPCRIT (McGuffin et al, 1991), a symptom checklist which generates standardised diagnoses. Four patients had no or inadequate case notes and for these people a semi-structured diagnostic interview was necessary. One of these patients refused all contact with the researchers and was excluded. Another was markedly cognitively impaired in addition to being deaf and blind. She did not cooperate with interview and was excluded from further analysis. The two remaining patients were not eligible: one had a bipolar affective disorder and the other had no psychiatric diagnosis.

\section{Interview procedure}

Patients were contacted only with the permission of their general practitioner, consultant or keyworker. Subject to consent, the research psychiatrist interviewed each patient and the research nurse interviewed the carer (where available) using the Cardinal Needs Schedule (Marshall et al, 1995). It comprises the following six scales.

Behaviour was assessed using the 'Rehabilitation Evaluation Hall and Baker'
(REHAB; Baker \& Hall, 1988), a widely used standardised behaviour scale which rates living skills such as communication and self-care (general behaviour, scale $0-160$ ), and disruptive or embarrassing behaviours such as violence, self-harm and shouting (disturbed behaviour, scale 0-14). Some questions had been slightly altered in an earlier study (Murray et al, 1996) to make them suitable for use in community settings.

The Manchester scale (Krawiecka et al, 1977) rates depression/anxiety on a scale of $0-8$; positive symptoms (hallucinations, delusions and/or incoherence of thought) on a scale of $0-12$; negative symptoms (psychomotor retardation, blunting of affect and/or poverty of speech) on a scale of $0-12$; and side-effects of psychotropic medication, including tardive dyskinesia, on a scale of $0-10$.

The Mini-Mental State Examination (MMSE; Folstein et al, 1975) is used to assess cognitive impairment (scale 0-30; higher scores indicate better cognitive function).

The Client Opinion Questionnaire is a structured interview that elicits the patient's views on current problems and needs.

The Carer Stress Questionnaire is a structured interview about problems encountered by the main carer.

The Additional Information Schedule collates information from the case notes and the carer on medical history, forensic history and other relevant clinical factors. These last three scales were specifically developed for the Cardinal Needs Schedule (Marshall et al, 1995).

These instruments together determine whether objective problems are present in eight clinical and eight social domains of functioning (Table 1). These become cardinal problems (a problem requiring action) if one, two or three of the following criteria are met: first, the patient is willing to accept help for the problem (the cooperation criterion); second, people caring for the patient are experiencing severe anxiety, annoyance or inconvenience as a result of the problem (the caregiver stress criterion); third, the problem is such that the health and safety of the patient and/or others are at risk (the severity criterion). Rules for deciding on the presence of a cardinal problem are not applied uniformly. For example, people who were unable to use community facilities would not have a cardinal problem in this area if they did not want help. On the other hand, behaviour that puts a patient at risk 
Table I Results of the needs assessment in patients

\begin{tabular}{|c|c|c|c|c|c|c|}
\hline Area of functioning & Objective problems & Cardinal problems & Suspended needs & PPDI & Needs & Intervention \\
\hline \multirow[t]{5}{*}{ Psychosis } & 31 & 27 & $\mathbf{I}$ & $\mathbf{I}$ & 25 & Atypical neuroleptic (4) \\
\hline & & & & & & Cognitive-behavioural therapy (I) \\
\hline & & & & & & Family intervention (I) \\
\hline & & & & & & Monitoring medication (2) \\
\hline & & & & & & Psychiatric assessment (I7) \\
\hline \multirow[t]{2}{*}{ Side-effects } & 39 & 33 & $\mathbf{I}$ & 5 & 27 & Change in medication (7) \\
\hline & & & & & & Psychiatric assessment (20) \\
\hline \multirow[t]{4}{*}{ Anxiety or depression } & 13 & II & 0 & $\mathbf{I}$ & 10 & Basic behavioural intervention (2) \\
\hline & & & & & & Medication (2) \\
\hline & & & & & & Psychological treatment (3) \\
\hline & & & & & & Support (3) \\
\hline Self-harm or violence & 5 & 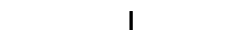 & 0 & 0 & 1 & Psychiatric assessment (I) \\
\hline \multirow[t]{2}{*}{ Organic disorder } & 34 & 29 & 0 & 7 & 22 & Monitoring of cognitive functioning (3) \\
\hline & & & & & & Specialist investigation (19) \\
\hline \multirow[t]{5}{*}{ Health } & 27 & 23 & 3 & II & 9 & Advice on aids (I) \\
\hline & & & & & & Coping advice (carer) (I) \\
\hline & & & & & & Coping advice (patient) (I) \\
\hline & & & & & & Specialist assessment (5) \\
\hline & & & & & & Specific treatment $(I)$ \\
\hline \multirow[t]{2}{*}{ Socially embarrassing behaviour } & 26 & 12 & 4 & 1 & 7 & Basic behavioural intervention (5) \\
\hline & & & & & & Psychological treatment (2) \\
\hline Drugs and alcohol misuse & I & 0 & 0 & 0 & 0 & \\
\hline \multirow[t]{2}{*}{ Domestic skills } & 41 & II & 1 & 3 & 7 & Home help (I) \\
\hline & & & & & & Specialist assessment (6) \\
\hline Finance and welfare & 39 & 3 & I & 0 & 2 & Remedial training (2) \\
\hline \multirow[t]{2}{*}{ Transport and amenities } & 40 & 10 & 0 & 4 & 6 & Remedial training $(I)$ \\
\hline & & & & & & Special transport (5) \\
\hline Literacy & I & 0 & 0 & 0 & 0 & \\
\hline Work & 0 & 0 & 0 & 0 & 0 & \\
\hline \multirow[t]{5}{*}{ Social life } & 49 & 20 & 2 & 0 & 18 & Coping advice (patient) (I) \\
\hline & & & & & & Medication (8) \\
\hline & & & & & & Sheltered leisure (6) \\
\hline & & & & & & Social stimulation programme (I) \\
\hline & & & & & & Structured daytime activity (2) \\
\hline \multirow[t]{2}{*}{ Hygiene and dressing } & 31 & 25 & 5 & 16 & 4 & Remedial training $(I)$ \\
\hline & & & & & & Supervised bathing and dressing (3) \\
\hline \multirow[t]{6}{*}{ Accommodation } & N/A & N/A & $\mathrm{N} / \mathrm{A}$ & $\mathrm{N} / \mathrm{A}$ & 14 & Bedsit (supported) (I) \\
\hline & & & & & & Flat (one bedroom) (3) \\
\hline & & & & & & Flat (supported) (2) \\
\hline & & & & & & Flat (two bedrooms) (I) \\
\hline & & & & & & Group home (24-h staffing) (3) \\
\hline & & & & & & Nursing home (4) \\
\hline Total & 377 & 205 & 18 & 49 & 152 & \\
\hline
\end{tabular}

PPDI, persistent problems despite intervention.

becomes a cardinal problem on the basis of severity even if the patient would not choose to accept any intervention. For each area of functioning the outcome for a cardinal problem must be one of the following: (a) a suspended need - a cardinal problem for which a suitable intervention exists and is in progress;

(b) a problem that persists despite intervention - a cardinal problem for which all suitable interventions have been tried and failed;

(c) a need - a cardinal problem for which a suitable intervention exists but which has not been given a recent adequate trial. 


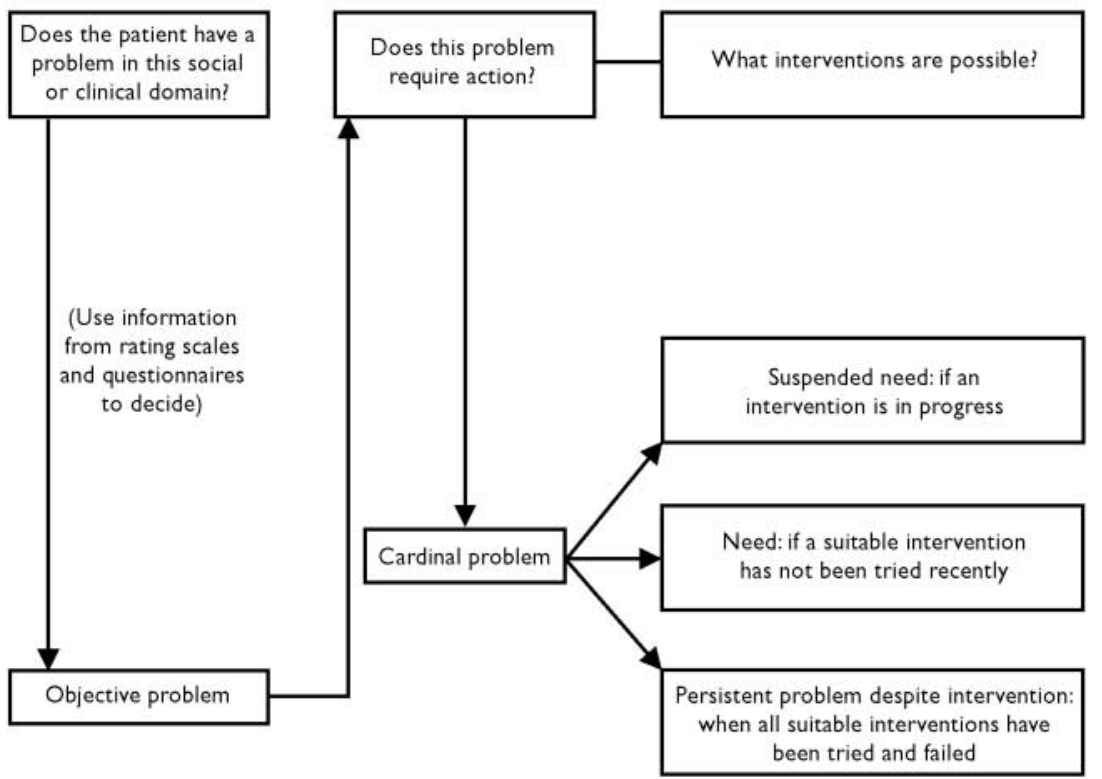

Fig. I Rules for determining needs.

The process that is followed in determining objective problems, cardinal problems, needs, suspended needs and persistent problems despite intervention is summarised in Fig. 1. This provides a very conservative assessment of needs. Lockwood (2000) summarised needs as 'a measure of the extent to which mental health services are failing to provide suitable care'.

\section{Statistical analysis}

Total numbers of objective problems, cardinal problems, needs, suspended needs and persistent problems despite intervention in the people interviewed were calculated for each social and clinical domain. Statistical analyses were performed using the Statistical Package for the Social Sciences, version 9.0 for Windows (SPSS, 1998). Mean scores and $95 \%$ confidence intervals are presented for comparisons of key sociodemographic, clinical and needs assessment variables. Levels of statistical significance are based on independent-sample $t$-tests. When re-analysed using non-parametric methods the levels of statistical significance are very similar.

\section{RESULTS}

A total of 95 patients appeared to meet all initial inclusion cirteria. The research old age psychiatrist (S.V.M.) made the final decision on each patient's diagnosis on the basis of structured examination of the case notes, information from the patient's doctors and keyworker, and his own clinical examination. This was especially important in view of the high level of cognitive impairment in these people. In five cases a relevant OPCRIT diagnosis was overruled: one patient had suffered from delirium due to benzodiazepine withdrawal, one had experienced an organic mood disorder, two were diagnosed as having Alzheimer's disease, and one had dementia with Lewy bodies. This left 90 patients. The possibility remains that some of the patients with recent onset of symptoms of psychosis had an underlying neurodegenerative disorder as the primary condition.

Eighty-one patients had schizophrenia, three had delusional disorder, and six had an atypical psychosis. The 1-year prevalence for non-organic, non-affective psychosis was 4.44 per 1000. Mean age was 73.9 years (s.d.=7.8, range 64-99); 29 patients $(32 \%)$ were male and 61 were female. The mean age at onset of illness was 51.1 years (s.d.=19.1, range 17-97); $53(59 \%)$ had onset after the age of 45 years. Fifty patients $(56 \%)$ were living in their own homes; 14 (16\%) were living in local authority or private residential and nursing homes; $12(13 \%)$ were in the NHS-private partnership home; $8(9 \%)$ were in long-stay wards of the mental hospitals; $5(6 \%)$ were in the community hospital; 1 was in the acute admission ward.

\section{Interviewed participants}

Fifty-eight participants (64\%) were interviewed. During the study year $12(13 \%)$ of the 90 eligible patients died and one moved to another part of the country before they could be interviewed. One patient (who had an OPCRIT diagnosis of schizophrenia and a known history of alcohol misuse) could not be traced despite visits to three different identified addresses. Eighteen patients $(20 \%)$ refused to participate, of whom 15 had a diagnosis of schizophrenia and 3 an atypical psychosis. They were of a similar age to the interviewed patients (mean 73.6 years $v .74 .9$ years; $P=0.5$ ). However, all but one were female and all were living in their own homes.

Of the 58 people interviewed, 37 (64\%) were female and 21 were male. The age range was 65-94 years with a mean of 75 years. Fifty-four patients $(93 \%)$ had a DSM-III-R diagnosis of schizophrenia, 2 (3\%) had a delusional disorder and 2 had an atypical psychosis. Twenty-four (41\%) participants were living in their own home; $13(22 \%)$ lived in a nursing or residential home; 11 (19\%) lived in the NHS-private partnership home; $5(9 \%)$ were in longterm psychiatric wards; 5 were in-patients in the community hospital or acute admission ward.

\section{Current symptoms and behaviour}

One patient did not cooperate with the assessment of current symptoms and sideeffects. Thirty-seven of the remainder $(65 \%)$ had clinically significant positive psychotic symptoms and $32(56 \%)$ had negative symptoms; 13 (23\%) had clinically significant depression and/or anxiety, 4 of whom reported suicidal ideas in the previous week. Tremor was identified by the research psychiatrist in 22 patients $(38 \%)$ and rigidity in $18(32 \%)$. Tardive dyskinesia was mild in $18(32 \%)$ and marked in $17(30 \%)$ of those who cooperated with clinical examination.

Cognitive impairment was a prominent feature. For the 53 participants who completed the MMSE the mean score was 20 (range 1-30). Thirty-two (60\%) of these people scored 25 or below, which was considered by Folstein et al (1975) to indicate clinically relevant cognitive impairment.

In 12 cases the REHAB scale was not completed because no carer was available for interview. The mean REHAB score for general behaviour in the remaining 46 participants was 75 (95\% CI 66.6-83.4, range $14-124)$. Twenty-six (57\%) had a 
general behaviour score above 70; using the original guidelines of Baker \& Hall (1988), if these people were on a long-stay ward it would be doubtful that they could ever live in the community. Only 14 of these 26 high scorers were in long-term hospital or partnership care; 9 were in a residential or nursing home, and 3 were at home, cared for by their family. On the disturbed behaviour scale, 31 participants $(67 \%)$ scored 1 or above, indicating some form of disruptive or embarrassing behaviour in the previous week.

\section{Needs assessment}

Table 1 shows that the 58 people interviewed had 101 needs for care in clinical domains and 51 in social domains (mean total 2.6 per person). Eleven patients $(19 \%)$ had no clinical need, 11 had one clinical need, 22 (38\%) had two, 10 (17\%) had three, and 4 (7\%) had four clinical needs. There was no need in any social domain in 27 patients (48\%), 19 (33\%) had a need in one domain, $6(10 \%)$ had needs in two, $4(7 \%)$ had needs in three, and $2(3 \%)$ had needs in four social domains. Only 5 patients had no need whatsoever. One patient in a long-stay hospital ward had a total of seven unmet needs.

The research team decided which interventions were most appropriate for needs in each domain using the guidelines in the Cardinal Needs Schedule. These are shown in the last column of Table 1.

\section{Comparison according to residence}

Clinical features and needs are compared in Table 2 for community residents, hospital in-patients and patients in the NHS-private partnership home. These analyses must be interpreted with caution in view of the small number of participants and because some variables are so complicated. For example, a need relates to the severity of a problem, the patient's and carer's attitudes, and what care professionals have done to help. Nevertheless, these comparisons can provide some insight into the functioning of local psychiatric services.

Clinically significant differences in group means for some variables emerge; as can be seen from the confidence intervals, some differences were statistically significant in spite of the small numbers involved. Cognitive impairment and negative symptoms were much worse in hospital and partnership-home patients compared with community residents. Side-effects of

Table 2 Comparison of clinical features and needs of patients resident in hospital, in the National Health Service-private partnership home and in the community

\begin{tabular}{|c|c|c|c|}
\hline & $\begin{array}{l}\text { Hospital }(n=10) \\
\text { Mean }(95 \% \mathrm{Cl})\end{array}$ & $\begin{array}{c}\text { Partnership home }(n=\mathrm{II}) \\
\text { Mean }(95 \% \mathrm{Cl})\end{array}$ & $\begin{array}{c}\text { Community }(n=37) \\
\text { Mean }(95 \% \mathrm{Cl})\end{array}$ \\
\hline Age (years) & $72.4(69.5-75.3)$ & $78.5(75.4-8 I .5)$ & 74.8 (7I.8-77.8) \\
\hline Age at onset (years) & $39.7(27.0-52.4)$ & $47.7(31.5-64.0)$ & $53.5(47.5-59.4)$ \\
\hline \multicolumn{4}{|l|}{ Clinical features } \\
\hline General behaviour & $67.7(56.2-79.2)$ & $88.7(70.4-107.0)$ & $79.1(57.9-100.2)^{1}$ \\
\hline Disturbed behaviour & $\mathrm{I} .4(0.7-2.2)$ & $2.8(1.2-4.4)$ & $2.0(1.0-2.9)^{\prime}$ \\
\hline Positive symptoms & $4.3(1.9-6.6)$ & $4.8(2.4-7.2)$ & $3.6(2.4-4.8)^{2}$ \\
\hline Negative symptoms & $7.2(3.7-10.7)$ & $8.2(5.8-10.5)$ & $3.4(2.0-4.7)^{2}$ \\
\hline Depression/anxiety & $0.3(0-0.6)$ & $0.7(0-1.8)$ & $1.6(1.0-2.3)^{2}$ \\
\hline Side-effects & $3.2(1.7-4.7)$ & $2.7(I . I-4.3)$ & $1.6(I .0-2.1)^{2}$ \\
\hline MMSE & $17.6(9.7-25.4)^{3}$ & $10.2(4.1-16.3)^{3}$ & $22.7(19.9-25.4)^{2}$ \\
\hline \multicolumn{4}{|l|}{ Objective problems } \\
\hline Social & $4.6(3.9-5.3)$ & $4.2(3.3-5.0)$ & $2.9(2.3-3.6)$ \\
\hline Clinical & $3.5(2.5-4.5)$ & $3.6(2.9-4.3)$ & $2.7(2.3-3.1)$ \\
\hline Total & $8.1(6.6-9.6)$ & $7.8(6.7-9.0)$ & $5.7(4.7-6.6)$ \\
\hline \multicolumn{4}{|l|}{ Cardinal problems } \\
\hline Social & $2.1(1.2-3.0)$ & $1.2(0.6-1.8)$ & $0.9(0.5-1.3)$ \\
\hline Clinical & $2.8(1.9-3.7)$ & $2.9(1.9-3.9)$ & $2.0(1.7-2.4)$ \\
\hline Total & $4.9(3.4-6.4)$ & $4.1(2.7-5.4)$ & $3.0(2.4-3.6)$ \\
\hline \multicolumn{4}{|l|}{ PPDI } \\
\hline Social & $0.5(0-I .0)$ & $0.6(0.3-1.0)$ & $0.3(0.1-0.5)$ \\
\hline Clinical & $0.3(0-0.6)$ & $0.6(0.1-1.2)$ & $0.4(0.2-0.6)$ \\
\hline Total & $0.8(0.2-1.4)$ & I.3 (0.5-2.0) & $0.7(0.4-I . I)$ \\
\hline \multicolumn{4}{|l|}{ Suspended needs } \\
\hline Social & $0.5(0-1.0)$ & $0.1(0-0.3)$ & $0.1(0-0.2)$ \\
\hline Clinical & $0.7(0-1.7)$ & 0 & $0.05(0-0.1)$ \\
\hline Total & $1.2(0-2.4)$ & $0.1(0-0.3)$ & $0.1(0-0.2)$ \\
\hline \multicolumn{4}{|l|}{ Needs } \\
\hline Social & I.8(0.9-2.7) & $0.4(0.1-0.8)$ & $0.8(0.4-I . I)$ \\
\hline Clinical & I.8(0.8-2.8) & $2.3(1.4-3.2)$ & $1.6(1.2-1.9)$ \\
\hline Total & $3.6(2.2-5.0)$ & $2.7(1.6-3.9)$ & $2.3(1.8-2.8)$ \\
\hline
\end{tabular}

MMSE, Mini-Mental State Examination; PPDI, persistent problems despite intervention.

I. $n=25$ (fewer community patients had a carer to complete the Rehabilitation Evaluation Hall and Baker (REHAB) scale.

2. $n=35$.

3. $n=9$.

medication were substantially more severe in the hospital patients compared with those living in the community. However, the community residents had the highest mean depression/anxiety scores (1.6): the difference appears clinically significant when compared with the mean for partnership-home patients $(0.7 ; P=0.17)$ and both clinically and statistically significant compared with the hospital in-patients $(0.3$; $P=0.04)$. Hospital in-patients had, on average, considerably more social needs for care (1.8) than those in the partnership home $(0.4 ; P=0.005)$ and the community residents $(0.8 ; P=0.009)$.

\section{Comparison of CMHT input}

Thirty-seven participants were living in the community, either in their own homes or in nursing or residential homes. Table 3 compares those receiving $(n=17)$ and not receiving $(n=20)$ care from the CMHT. The CMHT appears to be targeting a more seriously ill group. In particular, the teams' patients had more-severe negative symptoms of schizophrenia. On average, total needs were higher in those receiving care from the CMHT (2.9 v. 1.8; $P=0.027)$. However, the substantial number of needs in those not receiving multi-disciplinary mental health care should be noted. 
Table 3 Comparison of community patients receiving and not receiving input from the community mental health team (CMHT)

\begin{tabular}{|c|c|c|c|c|}
\hline & $\begin{array}{c}\text { On CMHT } \\
\text { case-load }(n=17)\end{array}$ & $\begin{array}{c}\text { Not on CMHT } \\
\text { case-load }(n=20)\end{array}$ & $\begin{array}{l}\text { Difference in means } \\
\qquad(95 \% \mathrm{Cl})\end{array}$ & $P$ \\
\hline Age (years) & 76.8 & 73.1 & $3.7(-2.3$ to 9.6$)$ & 0.220 \\
\hline Age at onset (years) & 58.6 & $48.8^{1}$ & 9.8 (- 1.8 to 21.4$)$ & 0.096 \\
\hline \multicolumn{5}{|l|}{ Clinical features } \\
\hline General behaviour & $71.1^{2}$ & $63.4^{3}$ & $7.7(-15.7$ to 31.2$)$ & 0.500 \\
\hline Disturbed behaviour & $1.0^{2}$ & $2.0^{3}$ & $-1.0(-2.5$ to 0.5$)$ & 0.180 \\
\hline Positive symptoms & 3.9 & $3.3^{\prime}$ & $0.6(-1.8$ to 3.1$)$ & 0.576 \\
\hline Negative symptoms & 5.5 & $1.5^{1}$ & $4.0(1.7$ to 6.3$)$ & 0.001 \\
\hline Depression/anxiety & 2.1 & $1.2^{1}$ & $0.9(-0.3$ to 2.2$)$ & 0.139 \\
\hline Side-effects & 1.9 & $1.2^{1}$ & $0.7(-0.4$ to 1.8$)$ & 0.188 \\
\hline MMSE & $20.2^{4}$ & $24.7^{1}$ & $-4.5(-9.7$ to 0.8$)$ & 0.097 \\
\hline \multicolumn{5}{|l|}{ Objective problems } \\
\hline Social & 3.6 & 2.3 & $1.3(0$ to 2.6$)$ & 0.053 \\
\hline Clinical & 3.4 & 2.2 & I.2(0.4 to I.9) & 0.004 \\
\hline Total & 7.0 & 4.5 & 2.5 (0.7 to 4.2$)$ & 0.008 \\
\hline \multicolumn{5}{|l|}{ Cardinal problems } \\
\hline Social & 1.3 & 0.6 & 0.7 (0 to I.5) & 0.061 \\
\hline Clinical & 2.6 & 1.5 & I.I (0.5 to I.7) & 0.001 \\
\hline Total & 4.0 & 2.1 & $1.9(0.7$ to 2.9$)$ & 0.002 \\
\hline \multicolumn{5}{|l|}{ PPDI } \\
\hline Social & 0.4 & 0.2 & $0.2(-0.2$ to 0.6$)$ & 0.339 \\
\hline Clinical & 0.6 & 0.2 & $0.4(0$ to 0.8$)$ & 0.062 \\
\hline Total & I.I & 0.4 & $0.6(0$ to $I .3)$ & 0.069 \\
\hline \multicolumn{5}{|l|}{ Suspended needs } \\
\hline Social & 0.2 & 0 & $0.2(0$ to 0.35$)$ & 0.052 \\
\hline Clinical & 0.06 & 0.05 & $0.01(-0.1$ to 0.2$)$ & 0.909 \\
\hline Total & 0.2 & 0.05 & $0.15(0$ to 0.4$)$ & 0.106 \\
\hline \multicolumn{5}{|l|}{ Needs } \\
\hline Social & 1.0 & 0.5 & $0.5(-0.2$ to I.I) & 0.181 \\
\hline Clinical & 1.9 & 1.2 & 0.7 (0 to I.3) & 0.037 \\
\hline Total & 2.9 & 1.8 & I.I (0.I to 2.1$)$ & 0.027 \\
\hline
\end{tabular}

MMSE, Mini-Mental State Examination; PPDI, persistent problems despite intervention.

I. $n=19$.

2. $n=14$.

3. $n=$ II.

4. $n=16$.

It is also a cause for concern that there were very few suspended needs. Among the whole group of patients who were not under the care of the CMHT there was no suspended need in any social domain and only one suspended clinical need. This indicates that little is currently being done to assist these patients in spite of their having, on average, more than two cardinal problems each.

\section{DISCUSSION}

\section{Needs for care}

This was clearly a very disabled group of patients. Even more important than the had, on average, 0.3 social needs and only 0.03 clinical needs.

\section{Reasons for shortcomings in care}

Lanarkshire has the second highest level of need in Scotland (using socio-demographic variables as a proxy measure) but by far the lowest per capita spending on mental health services (Accounts Commission for Scotland, 1998). There is a shortage of consultants both in old age and general adult psychiatry throughout the UK (Royal College of Psychiatrists, 1998). Lanarkshire has the lowest number of funded posts in Scotland and this has resulted in a lack of continuity of care. Similar shortages exist in all the mental health professions.

Depending on local policies, patients with chronic psychosis who reach the age of 65 years may go to either a new social work team, a new health care team or both. Three faculties of the Royal College of Psychiatrists (the faculties of rehabilitation psychiatry, old age psychiatry and general psychiatry) have described continuing uncertainty regarding whether old age psychiatrists should take over responsibility for these 'graduate' patients (D. Jolley, personal communication, 2002). General adult psychiatric teams can struggle with the increasing complexities of the management of patients with psychosis as they age. Also, they are often forced to prioritise young patients with more-acute illness.

\section{Accommodation}

Fourteen needs related to inappropriate accommodation. Local authorities face particular difficulties in housing the relatively small number of patients with functional psychotic illnesses, who often end up in mainstream nursing homes, living with patients with severe dementia despite having very different nursing needs. The NHSprivate partnership homes are a new development in the care of people with severe psychiatric and neuropsychiatric illnesses in Scotland. These facilities can only be welcomed when compared with the wards of Victorian asylums. In this study, patients in the partnership home had fewer social needs than any other group. Some shortcomings were identified which might have been due to lack of experience with this model of service provision. These NHSprivate partnership homes will not be successful if, for example, there is insufficient input from trained psychiatric nurses and consultants in old age psychiatry. 


\section{Implications for clinicians, managers and policy-makers}

The demonstration project investigated by the Team for Assessment of Psychiatric Services has shown that high-quality care can be achieved in this patient group (Trieman \& Wills, 1996; Trieman et al, 1999). However, our study provides evidence of serious shortcomings. It remains to be seen whether similar problems exist in other parts of the UK. These results raise serious questions about methods of working and targeting of patient groups. Systematic needs assessment could assist clinicians, managers and policy-makers in their efforts to provide decent care for our elders with schizophrenia, who are among the most vulnerable members of society.

\section{ACKNOWLEDGEMENTS}

We thank the staff of the Information and Statistics Division of the NHS in Scotland for their assistance. We also thank all the clinicians who helped us to identify and interview the patients. We are especially grateful to the patients and their families who participated in the study.

\section{REFERENCES}

Accounts Commission for Scotland (1998) Adult Mental Health Services. Bulletin I: Patterns of NHS Service Provision. Edinburgh: Accounts Commission for Scotland.

American Psychiatric Association (1987) Diagnostic and Statistical Manual of Mental Disorders (3rd edn, revised) (DSM-III-R). Washington, DC: APA

Baker, R. \& Hall, J. (1988) REHAB: a new assessment instrument for chronic psychiatric patients. Schizophrenia Bulletin, 14, 97-III.

Brewin, C. R., Wing, J. K., Mangen, S. P., et al (1987) Principles and practice of measuring needs in the longterm mentally ill: the MRC Needs for Care Assessment. Psychological Medicine, 17, 97I-981.

Carstairs, V. \& Morris, R. (1991) Deprivation and Health in Scotland. Aberdeen: Aberdeen University Press.

Folstein, M. F., Folstein, S. E. \& McHugh, P. R. (1975) 'Mini-mental State': a practical method for grading the cognitive state of patients for the clinician. Journal of Psychiatric Research, 12, 189-198.

Holloway, F., Rutherford, J., Carson, J., et al (1994) 'Elderly graduates' and a hospital closure programme. Psychiatric Bulletin, 18, 534-537.

Krawiecka, M., Goldberg, D. \& Vaughan, M. (1977) A standardised psychiatric assessment for rating chronic psychotic patients. Acta Psychiatrica Scandinavica, 55 , 299-308.

Leff, J. (ed.) (1993) The TAPS project: evaluating community placement of long-stay psychiatric patients. British Journal of Psychiatry, 162 (suppl. 19), I-56.

Lockwood, A. (2000) Autoneed: a computerised version of the Cardinal Needs Schedule. Computers in Mental Health, http://www.ex.ac.uk/cimh/sware/ autoneed. htm (last modified 27 January 2000).

\section{CLINICAL IMPLICATIONS}

- Asser tive treatment of patients with schizophrenia must be provided at all ages and must take into account the changing nature of health and social care needs.

- Regular psychiatric monitoring even in periods of apparent stability is essential for effective management of older patients.

- Comorbid cognitive impairment and physical illness in older patients with schizophrenia indicate the need for management by adequately resourced specialist old age psychiatry services.

\section{LIMITATIONS}

- Approximately a quarter of the available patient group did not participate in the interview phase of the study. Their needs are likely to be different from those of the patients who were interviewed.

- The Cardinal Needs Schedule may not be sensitive to some specific needs of elderly patients with major mental illnesses.

- This is a local study that may or may not be generalisable to other areas.

SEAMUS V. MCNULTY, MRCPsych, Ayrshire Central Hospital, Irvine; LAING DUNCAN, RMN, Gartnavel Royal Hospital, Glasgow; MARGARET SEMPLE, MRCPsych, Royal Dundee Liff Hospital, Dundee; GRAHAM A. JACKSON, MRCPsych, Leverndale Hospital, Glasgow; ANTHONY J. PELOSI, FRCP, Hairmyres Hospital, East Kilbride, Scotland, UK

Correspondence: Dr Seamus McNulty, Department of Psychiatry, Ayrshire Central Hospital, Irvine KAI2 8SS, Scotland, UK. E-mail: seamus.mcnulty@aapct.scot.nhs.uk

(First received 24 May 2002, final revision 8 October 2002, accepted 21 October 2002)

Marshall, M. (1994) How should we measure need? Concept and practice in the development of a standardised schedule. Philosophy, Psychology and Psychiatry, I, 27-36.

\section{_ , Hogg, L., Lockwood, A., et al (1995) The} Cardinal Needs Schedule: a modified version of the MREC Needs for Care Schedule. Psychological Medicine 25, 605-617.

Matthew, G. K. (197I) Measuring need and evaluating services. In Portfolio for Health. Problems and Progress in Medical Care (ed. G. McLachlan), pp. 27-46. London: Oxford University Press.

McGuffin, P., Farmer, A. \& Harvey, L. (1991) A polydiagnostic application of operational criteria in studies of psychotic illness: development and reliability of the OPCRIT system. Archives of General Psychiatry, 48 645-650.

McLoone, P. (2000) Carstairs Scores for Scottish Postcode Sectors from the 1991 Census. Glasgow: Public Health Research Unit.

Murray, V., Walker, H. W., Mitchell, C., et al (1996) Needs for care from a demand led community psychiatric service: a study of patients with major menta illness. BMI, 312, 1582-1586.

$\ldots, \ldots, \ldots$, et al (1998) Structured needs assessment as an outcome measure in psychosis: a comparison of two contrasting services. Schizophrenia Research, 29, 193.

Perkins, R. E., King, S. A. \& Hollyman, J. A. (1989) Resettlement of old long-stay psychiatric patients: the use of the private sector. British Journal of Psychiatry, I55, 233-238.
Rodriguez-Ferrera, S. \& Vassilas, C. A. (1998) Older people with schizophrenia: providing services for a neglected group. BMJ, 317, 293-294.

Royal College of Psychiatrists (1998) Annual Census of Psychiatric Staffing (Occasional Paper OP46). London: Royal College of Psychiatrists.

SPSS (1998) SPSS for Windows Base System User's Manual. Release 9.0. Chicago, IL: SPSS.

Stevens, A. \& Gabbay, J. (1991) Needs assessment. Health Trends, 123, 20-23.

Trieman, N. \& Wills, W. (1996) The psychogeriatric population: in transition from hospital to community based services. In Care in the Community: Illusion or Reality? (ed. J. Leff), pp. 109-120. Chichester: John Wiley \& Sons

_ , Leff, J. \& Glover, G. (1999) Outcome of long stay psychiatric patients settled in the community. BMJ, 319, $13-16$

Wing, J. K. (1992) Epidemiologically-based Mental Health Needs Assessment. Review of Research on Psychiatric Disorders (ICD-10, F2-F6). London: Royal College of Psychiatrists, College Research Unit.

World Health Organization (1978) Ninth Revision of the International Classification of Diseases and Related Health Problems (ICD-9). Geneva: WHO.

- (1992) Tenth Revision of the International Classification of Diseases and Related Health Problems (ICD-10). Geneva: WHO. 